\title{
Study on the value of Zheng He's spirit to the moral education of Maritime College Students
}

\author{
Shijie Yan \\ Navigation College, Shandong Jiaotong University, Weihai, China
}

Keywords: Marine power; the spirit of Zheng He; moral education in Colleges and Universities

\begin{abstract}
Zheng He's voyage to the west is difficult and dangerous. By virtue of the conditions of heaven, earth, and human beings, Zheng He successfully completed his mission. Although the history of the Western Ocean has passed, Zheng He's spiritual strength displayed on voyage has not been forgotten by history. China's shipping industry started with Zheng's "cloud sail soaring". In this regard, Zheng He is selected as an example, and "Zheng He spirit" is used to stimulate the patriotic love of the university students of contemporary maritime colleges and universities, to report a strong state of the country, to reverse the serious situation of the people's lax shipping industry and the loss of the crew. Enhance the spiritual realm of maritime students and help realize the dream of ocean power.
\end{abstract}

\section{Introduction}

Example is a silent textbook, the most inspiring guide sign, guiding people forward with their fresh deeds and strong spiritual strength. In the realization of the great rejuvenation of the Chinese dream today, we must regain spiritual strength, arm people with correct values, and promote the awakening of all walks of life. Especially in the development of the shipping industry today, the maritime colleges and universities, as the transportation land of the shipping talents, should select the example of Zheng He, integrate their spiritual strength with the construction of moral education in Colleges and universities, make the sound of their spiritual sound into every corner of the construction of moral education in Colleges and universities, and become the strongest voice of the time generation, thus promoting the moral of the college students. Raising the level and helping the development of the shipping industry.

For the state, the spirit of Zheng He is an indispensable spiritual pillar. The patriotism contained in Zheng He's spirit is an important embodiment of the socialist core values, and the demonstration role of the people is beneficial to the continuous improvement of the national quality; for the society, the harmonious spirit contained in the spirit of Zheng He is to maintain social stability. The good medicine is a cohesion adhesive; for individuals, the spirit of innovation contained in Zheng He's spirit is a catalyst to enhance personal charm and stimulate personal fighting, which is conducive to the continuous transcendence of the self. Therefore, whether it is for the state, society or individuals, it is imperative to study the spirit of Zheng He.

As a whole, the degree and recognition of Zheng He's spirit of the college students in navigation colleges and universities are generally positive. However, some college students are also affected by bad social atmosphere. They are very sharp, deny the achievements of Zheng He's voyage and ignore the spiritual strength of their voyage. It was not a support for Zheng He, but a derogatory and irony. They doubted and alienated the spirit of Zheng He, with a partial view that Zheng He's "quest for peace" was not the embodiment of the traditional Chinese virtues, but a "Coward theory" and "low theory"; and the students were singing the contrary, that Zheng He was forced to go to the west, not the voluntary initiative; and more of the world held the world. In the change and development of the principle that the times are constantly evolving, specific times have a specific historical background, Zheng He's spiritual power in the west is purely out of date, for the present is not synchronous, no need to repeat and so on. In view of these misunderstandings, it is necessary for us to vigorously publicize the deeds of Zheng He's voyages to the West and his spiritual strength, to reverse these extreme comments, to instill correct values to college students and to reshape the 
positive energy.

\section{An overview of Zheng He's spirit}

According to historical records, Zheng He's surname is Ma, and "the first three guarantees" is called ma Sanbao. It was born in Kunming, Yunnan, in 1371. Zheng He's ancestors emigrated to Yunnan at the beginning of Yuan Dynasty, which was a noble family at that time. He is very handsome and familiar with the art of war. He is brave and good at fighting, and has strong military command ability. He grew up in the Ming army and had strict organizational discipline. When Zheng He became an adult, he followed Yongle to participate in the battle of Jing Jin. He fought a bloody battle, went through life and death, and went through several major battles, all of which were successful. For this reason, Yongle awarded Zheng He the rank of "imperial Constable eunuch" and ordered him to sail over the Western Ocean with more than 20000 officers and men.

Zheng He's seven voyages to the West are difficult and dangerous. But the Zheng He fleet completes its mission by means of advanced technical equipment and firm spiritual belief. Zheng He's voyage is not a struggle and a bullying, but a harmony and friendship; it is not the solitude of the cultures of all countries, but the resonance of a hundred flowers, not the closed and self locked Gracilaria, but a platform for opening and blending.

Zheng He's voyage can be called "China's advance and its surprise." From 1405 to 1433, during the 28 years, Zheng He overcame 160 thousand miles of hardships and dangers and led the great troops to accomplish the mission of the seven voyages to the West. During the visit, more than 30 countries, including Africa, were interviewed. During the voyage, there are many difficulties, and all kinds of unpredictable natural disasters have encountered many man-made persecution.

A core point of historical materialism is to understand the essence of a thing and a spiritual phenomenon, and not to find the explanation from the thing itself, but to search for the historical events and practical activities that produce this and the spiritual phenomenon. Therefore, in order to explore the origin of Zheng He's spirit, we must return to the specific era in which we perceive and comprehend. Through consulting the classics, the author generalizes the connotation of Zheng He's spirit as the unswervingly patriotic spirit, the open and inclusive spirit of peace and the innovative spirit of chopping waves.

\section{The concrete embodiment of Zheng He's moral moral value}

Maritime college students are the reserve force for realizing the dream of a powerful marine country. The spirit of "patriotism, peace and innovation" embodied in Zheng He's voyage is in the same vein as the socialist core values advocated at present. It is necessary to be the fresh material for the moral education of the college students in the contemporary maritime colleges and universities.

\subsection{The leading value of life goals}

Leading is to lead the wrong ideas with correct thinking, and the idea of civilization infect barbarous ideas. In order to reverse the phenomenon that the current college students' life goals are not clear, the navigation colleges should choose Zheng He as an example, take Zheng He's spirit as the fodder, and strengthen the construction of moral education for college students in navigation colleges. The spirit of Zheng He's guidance to the life goals of college students lies in the following two aspects:

Lead the university students to establish the ideal and belief of patriotism. The crew in the outside, not only represent the individual, but represent the whole country, so we must use the spirit of Zheng He as a code of conduct. When facing the temptation of interest, we must always keep in mind that the heart of patriotism is greater than everything. In the face of damaging national interests, we must fight back with wisdom and strive for more rapid development. It is the belief of every nautical man that "Gou Li lives and dies, and it is a blessing to avoid it".

To guide college students to form the value orientation of collectivism. The smooth operation of 
a ship can not be separated from the cooperation of every link. Every link must be done well and must not be penny wise and pound foolish. In the face of task assignment, we should give full play to the idea of collectivism and set up a sense of overall situation, not because of the complex task or the discomfort of the environment. The navigation colleges should educate the college students with the fresh examples of Zheng He's voyage to the west, so that they can more intuitively feel the greatness of the collective power and recognize Zheng Hejing. The value of collectivism in the spirit is more demonstrative to the behavior guidance of College Students' real life.

\subsection{Disseminating the harmonious relationship value}

It is beneficial to the education of the peace spirit of college students. Zheng He's spirit of peace is highly consistent with the current spirit of peace advocated by general secretary Xi Jinping. The content of Zheng He's spirit is closely linked with the times. It can touch the mind of college students, enhance the ability of college students to deal with conflict friction, stimulate their passion and ambition, thus better contribute their strength to the shipping industry.

It is beneficial to the formation of the harmonious spirit of college students. Zheng He's voyage to the west is a precious and respecting peace spirit. It has effectively solved the conflict with other countries, promoted the exchange and cooperation between the countries and abroad, opened up the overseas market and played a harmonious spirit. Zheng He led more than 20 thousand officers and soldiers to open the voyage, the number of people unprecedented, the situation is also complicated. Leading such a huge crowd will always have a disagreement, and the environment for crew work is relatively closed to the sea. It is easy to get tired and produce negative energy, which leads to the situation of depolarization, and it is easy to crack down on the morale of the crew. When these problems arise, he uses the spirit of harmony to teach, unite people's hearts, work hard and cooperate with each other to complete the mission smoothly. Therefore, Zheng He's spirit of harmony has set a good example for students of Maritime Universities.

On the one hand, in the campus, the spirit of Zheng He is embodied in the sense of obedience. In order to cultivate excellent shipping talents, nautical colleges and universities choose to use semi military management mode, which can cultivate the cooperative spirit of college students. However, high intensity training will inevitably make college students have a conflict of emotion. Many students can not bear this kind of training and choose to be "deserters", in this case, navigation class. The builders of moral education in Colleges and universities must use the spirit of Zheng He to refer to the bow. In the sense of their spirit, students can understand the importance of obedience to the spirit and promote the development of school work. On the other hand, in practice, the spirit of Zheng He embodies the spirit of cooperation. The identity of maritime college students is special. The carrier of their work is ship. The ship's structure is complex and integral. The operation of the ship needs the effective operation of the various departments. The smooth completion of the navigation requires the coordination of everyone. This requires the crew to play the spirit of Zheng He in the face of the task and learn to unite and cooperate with them. In the case of disagreement, the crew should seek to communicate with each other in a calm manner. To the right answer. At the same time, the crew should learn to take the overall situation as the major, to follow the instructions of the captain, to carry forward the collectivist spirit of Zheng He, and not to shrink from the difficulties. Only if everyone is doing his own job well, the whole body can operate harmoniously and complete the shipping activities smoothly. Therefore, the crew must take Zheng He as an example, internalize the spirit of Zheng He, constantly give his own strength, and make his heart balance. When the individual and himself, the individual and the others can be in a harmonious state, the voyage will be completed successfully.

\subsection{The motivational value of self transcendence}

Zheng He is praised by the world for his real behavior. The college students in navigation colleges and universities learn the historical facts of Zheng He's voyage and internalize the spirit of Zheng He, which can not only stimulate the patriotism, but also improve their own personal accomplishment and their ability to innovate and practice. 


\section{The way to realize the value of Zheng He's moral education in Maritime Universities}

The cultivation process of moral education value is the process of transmitting correct values to college students and leading them to improve their personal qualities and achieve their goal in life. The spirit of Zheng He, which is condensed by Zheng He's voyage, has strong influence and is a vivid interpretation of the correct values of contemporary college students. Therefore, in advocating the cultivation of moral values of college students today, we must implement them through various paths.

\subsection{Firm ideal path}

Ideals and beliefs are vital to a person's growth and to the development of a country. Therefore, Maritime Universities should strengthen their ideals and beliefs from various paths.

Arouse the students' patriotism and love the sea emotion. Zheng He's love for the ocean is direct, and his love for the motherland is strong. Therefore, we must educate the majority of students to firmly establish the ideals and beliefs of loving the motherland and rational patriotism. University students have special status and special significance. They are the builders of the motherland, and we should strengthen patriotic education. The most traditional way for university students to accept knowledge is classroom, though traditional, but it has strong guidance.

Encourage college students to have a strong sense of innovation. In the past and present, the people of our country have lived the fine quality of life with the good quality of hard work and willing to do it. However, the times are progressing, the society is developing, and only innovation can lead a good day, and the country will be in an invincible position. The Zheng He era created the first complete map of the world, and constantly innovated the shipbuilding technology, improved the sailing ships, and explained the innovation to the world by practical action. Because of the particularity of their profession, maritime college students should pay more attention to the cultivation of innovative spirit.

\subsection{Pay attention to the effective path}

The force of spirit encourages people to do different things with their silent effect. Zheng He's spirit is great and strong infectious. Therefore, it is necessary to put the spirit into practice, to avoid the flow of form, not to declare the subject, to scratch, to do a good job, so that Zheng He's spiritual activity has the scale and momentum, guiding the students to move in the right direction.

- Exploring Zheng He's spiritual integration mechanism

- Updating the path of moral education in Colleges and Universities

\subsection{Advocating a harmonious path}

Since the eighteen Party's Congress, general secretary Xi Jinping has stressed the importance of taking the road of peaceful development and emphasizing "harmony is the most precious". Therefore, the navigation colleges should take "the spirit of peace" as the material of Zheng He spirit, carry out "peaceful thought" education to college students, cultivate their consciousness of harmonious coexistence, and improve their ability to deal with affairs. Better development of China's shipping industry.

Strengthen the cultivation of the harmonious spirit. Zheng He, in the face of the overall situation, in the face of the appointment of Ming Tai $\mathrm{Zu}$, without complaining, to play their advantages, with the collective spirit of cohesion, the Zheng He fleet successfully completed the mission. Therefore, maritime college students should learn this spirit and constantly enhance their collective consciousness.

Carry out the activities of unity and cooperation. It is precisely by virtue of harmonious coexistence with the team and sincere cooperation that he fulfilled his mission. For the cultivation of Zheng He's spirit, in addition to the reform of teaching, colleges and universities should pay more attention to the transformation of the external environment, and the culture of the dormitory is being paid more and more attention at present. 


\section{References}

[1] Zheng Chengjun: the guidance and construction of ideals and beliefs. Beijing: Tsinghua University press, 2010

[2] Shi Shuchen: "leading theory: A Study on the leading role of moral education in Colleges and Universities under multicultural background". Beijing: People's publishing house, 2011

[3] Han Qing: the history of modern Chinese shipping development. Dalian: Dalian Maritime University press, 2012

[4] Shi Chunlin and Jiang Xiumin: Study on the international main thoroughfare and its safety assurance. Beijing: Current Affairs press, 2015

[5] Hu Qi and Chen Haiyan: a comprehensive review of the socialization of moral education in Colleges and universities. Hangzhou: Zhejiang University press, 2016

[6] Wang Lilin: the theory and practice of brand guiding university campus culture and brand building. Beijing: China Book Publishing House, 2017 